\title{
Comparison of ankle joint kinematics of a single athlete during an ankle inversion sprain incident and normal non-injury motions
}

\author{
Zoe YS Chan', Sophia CW Ha2 ${ }^{2 *}$, Daniel TP Fong ${ }^{3}$, KM Chan $^{2}$ \\ From 4th Congress of the International Foot and Ankle Biomechanics (i-FAB) Community \\ Busan, Korea. 8-11 April 2014
}

\section{Introduction}

The purpose of this study was to compare the ankle joint kinematics including the angles, and their respective angular velocities of a tennis player during an ankle sprain incident and normal non-injury motion. And to deduce whether the sideward cutting motion of the athlete is an intrinsic factor to an ankle sprain.

\section{Methods}

Model-Based Image Matching (MBIM) motion analysis technique allows us to understand the leg movement quantitatively by analyzing the three-dimensional human motion. With validation, it has been used to obtain ankle kinematics during ankle sprain incidents in various sports [1]. In this study, a sideward cutting motion performed by a female athlete was compared against her injured incident reported in 2012 [2].

\section{Results}

Figure 1 and figure 2 show the right ankle kinematics profile of inversion, internal rotation, and plantarflexion during a sideward cutting motion to the right. Previously,

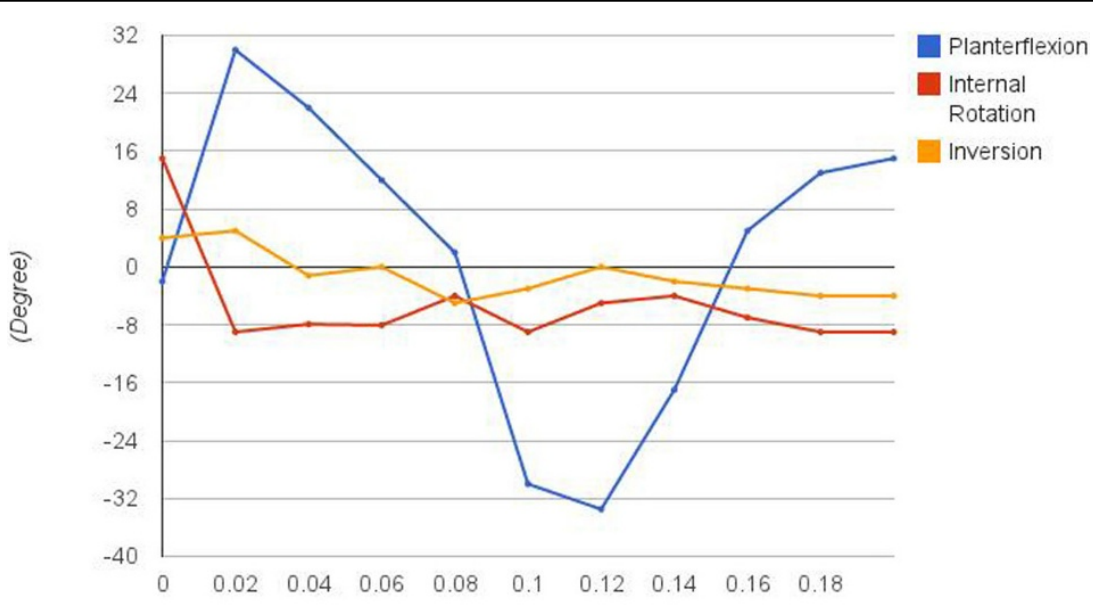

Time (sec)

Figure 1 Profile of joint orientation. Joint orientation

\footnotetext{
* Correspondence: sophiaha@cuhk.edu.hk

${ }^{2}$ Department of Orthopaedics and Traumatology, Prince of Wales Hospital,

Faculty of Medicine, The Chinese University of Hong Kong, Hong Kong

Full list of author information is available at the end of the article
} 


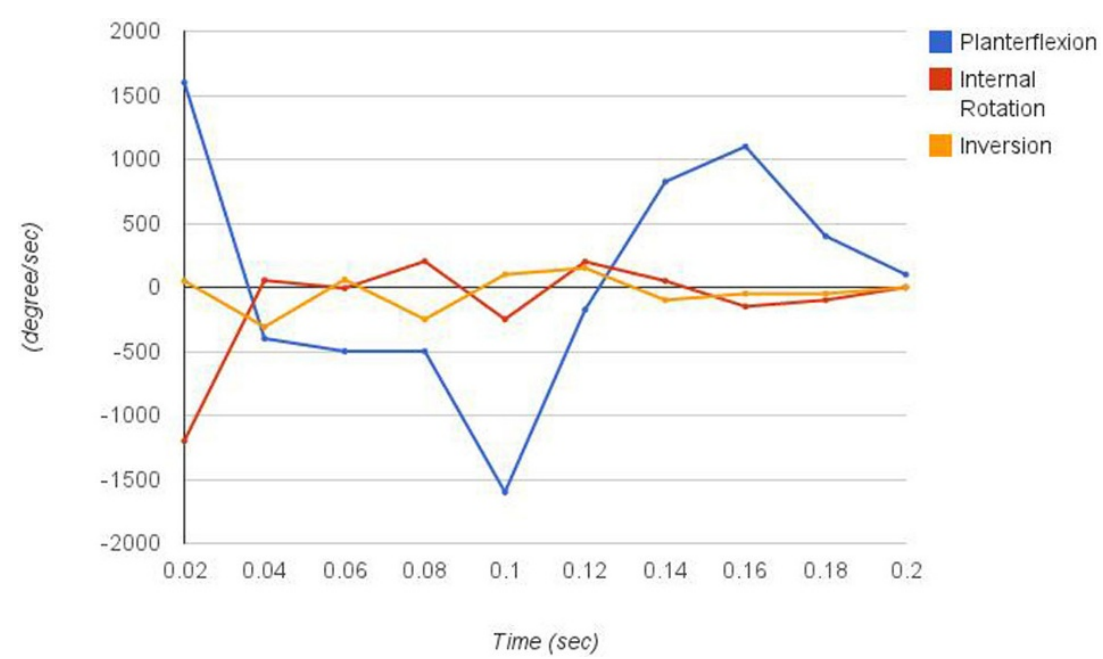

Figure 2 Profile of angular velocities. Joint velocity

the same athlete got injured performing a similar motion, regarding that incident, her peak inversion angle was reported to be $67^{\circ}$, which happened 0.17 second after foot strike [2]. The peak inversion angle of this case is $5^{\circ}$, significantly smaller compared to the injured case. The range of inversion angle was $5^{\circ}$ eversion to $5^{\circ}$ inversion. The degree of fluctuation of the angle of plantarflexion is greatest among the 3 planes of motion. It ranges from $-33.5^{\circ}$ to $30^{\circ}$. The peak velocity is $1600^{\circ} / \mathrm{sec}$ for both ways, doriflexion and plantarflexion.

\section{Conclusion}

This study further demonstrates that the sideward cutting motion does not require internal rotation and inversion, instead, ankle goes from plantarflexed to doriflexed, and then back to plantarflexed in a short time. An inverted ankle orientation on landing could be the inciting event of an ankle sprain when performing similar motion. However, a rapid joint motion in the plantarflexion/doriflexion plane is not likely to cause an ankle sprain. Therefore, the risk of performing the sideward cutting depends mostly on the ankle orientation during landing.

\section{Authors' details}

'Division of Biomedical Engineering, Department of Electronic Engineering, The Chinese University of Hong Kong, Hong Kong. ${ }^{2}$ Department of Orthopaedics and Traumatology, Prince of Wales Hospital, Faculty of Medicine, The Chinese University of Hong Kong, Hong Kong. ${ }^{3}$ School of Sport, Exercise and Health Sciences, Loughborough University, Leicestershire LE11 3TU, UK.

Published: 8 April 2014

\section{References}

1. Mok KM, Fong DTP, Krosshaug T, Hung ASL, Yung PSH, Chan KM: An ankle joint model-based image-matching motion analysis technique. Gait and Posture 2011, 34(1):71-75
2. Fong DTP, Ha SCW, Mok KM, Chan CWL, Chan KM: Kinematics analysis of ankle inversion ligamentous sprain injuries in sports - five cases from televised tennis competitions. The American Journal of Sports Medicine 2012, 40(11):2627-2632.

\section{doi:10.1186/1757-1146-7-S1-A28}

Cite this article as: Chan et al: Comparison of ankle joint kinematics of a single athlete during an ankle inversion sprain incident and normal non-injury motions. Journal of Foot and Ankle Research 2014 7(Suppl 1): A28.

\section{Submit your next manuscript to BioMed Central} and take full advantage of:

- Convenient online submission

- Thorough peer review

- No space constraints or color figure charges

- Immediate publication on acceptance

- Inclusion in PubMed, CAS, Scopus and Google Scholar

- Research which is freely available for redistribution 